\title{
Exploration on the Construction Path for New Engineering Based on Interdisciplinary Integration
}

\author{
Xiaojun $\mathrm{Ma}^{1}$, Ze Zhang ${ }^{1}$ and Chunjiang $\mathrm{Li}^{1,2, *}$ \\ ${ }^{I}$ School of Mechanical Engineering, Jiamusi University, Jiamusi, Heilongjiang 154007, China \\ ${ }^{2}$ School of Educational Science, Mudanjiang Normal University, Mudanjiang, Heilongjiang, 157011, China \\ *Corresponding author e-mail: jmslcj@ sohu.com
}

\begin{abstract}
New engineering construction is an important strategic decision and deployment for higher engineering education to adapt to the new economy and industry development. Based on the present reform on engineering education and the characteristics of subjects, this paper introduces the ideas and measures to build new engineering from the following four aspects: the optimization of professional structure, the talent training mode reform, comprehensive and coordinated education and evaluation of teaching quality, aiming to build an interdisciplinary training system for senior ability-oriented engineering talents.
\end{abstract}

Keywords: new engineering; optimization of professional structure; talent training mode; coordinated

education; evaluation of teaching quality

\section{INTRODUCTION}

At present, a new round of scientific and technological revolution and industrial transformation is accelerating around the world, and the new economy featuring new technologies, new forms of business, new industries and new models is booming. Therefore, it is urgent to train many diversified and innovative senior engineers and scientists. In 2017, the Ministry of Education launched the research on the development of "new engineering" to accelerate its construction so as to actively adapt to and usher into the new future-oriented economy. On February 18, the Development Strategy Seminar of Higher Engineering Education was held in Fudan University with the "Fudan Consensus" for new engineering construction formed. On April 8, a seminar on new engineering construction was held in Tianjin University. In this seminar, "Tianda Action Plan" was put forward, which made the "new engineering construction road map" clear; On June 9, The Establishment of Expert Group for New Engineering Research and Practice and The First Conference, held by the Ministry of Education in Beijing, deliberated and approved the Guideline on Engineering Research and Practice Project (Beijing Guideline), which comprehensively launched and systematically deployed the construction of new engineering. From "Fudan Consensus" to "Tianda Action", and then to "Beijing Guideline", it constitutes the "trilogy" of new engineering construction, initiates the talent cultivation, and blazes a trail for engineering education reform.

In recent years, by focusing on the needs of industries in health, manufacturing, education and culture, Jiamusi university issued Opinions of Jiamusi University on Promoting and Implementing the Integration of
Production-Study-Research while taking national and regional major strategies and key industries, the all-around revitalization on Heilongjiang and the upgrading of Jiamusi into consideration. Guided by the ideological and political curriculum, we will carry out the fundamental task of cultivating people through virtue and promote comprehensive educational reforms such as industry-education coordination, coordination between medicine and education, the building of new countryside, new city, new industry, new environment, excellence Plan, and innovation and entrepreneurship education. We will take root in the fertile soil of Sanjiang, uphold the black soil civilization, and fulfill the mission of protecting border areas culturally. The school takes "industry-study-research-use" collaborative education as an important basis for the reform of talent training mode, gives full play to the "local" and "comprehensive" advantages of our school, and establishes an "output-oriented" new mode with strengthening foundation and promoting interdiscipline, where "schools are the subject, enterprises serve as leading role, government give guidance and market plays its function". Furthermore, a total of 117 regional and industrial off-campus innovation practice bases have been set up, and a new platform has been set up for the integration of industries, universities, research institutes and users.

As the only local comprehensive university having the majors of medicine and engineering in Heilongjiang province, our university sets up medicine department and builds Heilongjiang provincial key laboratory of oral biomedical materials and clinical application, engineering center for stomatology and applied undergraduate demonstration construction professional cluster featured by stomatology and material science in order to promote the "industry-study-research-use" and "medical education collaboration". Besides, we are planning to build regional 
medical center. In order to actively serve the new industrialization, the university has signed "industry-study-research-application" strategic cooperative agreements with Peking University Health Science Center, China National Medical Device Co., LTD., Jiamusi Municipal Government and Jiamusi Medical and health enterprises. A "complete system" of new dental implants has been formed, which integrates the production, research and application, improved the technique of oral products, driven the high-end development of oral materials and products in Heilongjiang province and filled the gap in the domestic oral product market. Thus, it has obvious advantages and characteristics to promote collaborative education characterized by the integration of "industry-study-research-use". At present, aiming at the connotation and requirements of the new engineering, our university is oriented toward ability improvement to strengthen the construction of the new engineering from four aspects, namely, the optimization of the professional structure, the reform of the talent training mode, the comprehensive collaborative education, and the evaluation of teaching quality.

\section{TO OPTIMIZE SPECIALTY STRUCTURE UNDER THE BROADER CATEGORY OF ENROLLMENT AND CULTIVATION}

The greatest expansion for the engineering education reform by the construction of new engineering lies in the discipline specialty structure, and the new engineering specialty should serve as a leading role, which is characterized by its function of integration, innovation, cross-boundary, and development [4]. Central South university is oriented toward national strategic needs and social needs and breaks the barriers of colleges and disciplines according to the principle of "adaptation, guidance, interdiscipline, promotion". Moreover, it recruits students and trains students under larger categories according to first-level disciplines and similar disciplines and scientifically and reasonably integrates the existing 99 majors into 25 categories (including non-engineering majors), thus building a group of distinctive discipline and specialty groups with obvious advantages.

\subsection{Accelerating the upgrading of traditional disciplines and developing new ones}

It is necessary for the university to take the initiative to serve a series of major strategies proposed by the state, which is the starting point of the construction of new engineering. Therefore, the university upgrades and transforms traditional disciplines according to the characteristics of disciplines. Based on the development and utilization of national resources, it should accelerate the upgrading of medical biomaterials, biomedical engineering, and robotics engineering, meet the needs of the development strategy of the Belt and Road and strengthen the connotation construction and internationalization process of medical and industrial professional clusters. Meanwhile, it should attach great importance to the transformation from machinery, material, electronic information, automation and control into intelligent manufacturing and green manufacturing according to the deployment of "Made in China 2025".

\subsection{Taking the initiative to lay out new engineering and building new disciplines}

The characteristics of new engineering construction are to actively meet the industrial development needs and lead the development of new industries, new technologies and new formats. To this end, the university has bred new engineering majors through interdisciplinary integration. Relying on computer science and technology, information and communication engineering, mathematics and other disciplines, the university has set up the major of "intelligent manufacturing engineering" to meet the needs of multi-disciplinary, interdisciplinary and all-round high-quality talents for major projects.

\section{TO CARRY OUT THE REFORM OF THE STUDENT-CENTERED TALENT TRAINING MODEL}

The goal to build new engineering is to train excellent engineering talents to meet social development needs. Adhering to the "student-centered" education philosophy, the university has taken a series of measures centering on the construction of curriculum system, teaching content and methods to improve students' comprehensive ability.

\subsection{Developing an interdisciplinary training program to foster students' adaptability}

It should keep up with the new engineering to strengthen the connotation construction of professional talent training and emphasize the interdisciplinary integration of training programs. At the same time, it should pay attention to cultivate students' ability to adapt to changes and allow students to choose courses independently according to their professional interests and career plan. Therefore, through the scientific and reasonable setting of curriculum modules, the curriculum system which organically integrates "general educational courses, disciplinary educational courses, professional educational courses and personality development course" with clear structure and appropriate proportion should be set up. With the goal of fostering students' humanistic quality and lifelong learning ability, it should strengthen general education to lay a broad foundation for students and build modular courses with diverse levels and interdisciplines. In addition, with 
interdisciplinary curriculum as the breakthrough point, it's necessary to coordinate teachers from different disciplines to interdisciplinary curriculum group featured by its integration and universality with temporal spirit.

\subsection{Promoting "innovative practice ability training plan" to train students' critical thinking ability and creating thinking ability.}

In 2018, the university implemented a three-year revitalization action plan and fully implemented the basic system of teaching undergraduates by professors and associate professors. At present, 100 percent of undergraduate students are taught by professors and associate professors. In order to transform professors from "standing on the platform" to "teaching well on the classroom" and promote the transformation of students from "passive learning" to "active learning", the university has implemented the "comprehensive reform on undergraduate education" since 2013, which changes the traditional cramming education, emphasizes the students' dominant role in the teaching process, implements "interactive" teaching, small class discussion teaching, strengthens management and assessment in the teaching process and pays attention to the cultivation of students' comprehensive ability. A number of open, interactive, flexible and diverse classes have been constructed, and flexible and harmonious teaching modes such as discussion, case study and interactive teaching have been formed to improve students' independent learning and research-based learning ability. In the new engineering construction, "innovation practice ability training plan" should be emphasized to make further effort to observe and evaluate teaching process from multiple aspects such as from experts, colleagues and students and center on five basic requirements featured by "student-centered teaching concept, scientific teaching design, a well-structured teaching team, open teaching mode, comprehensive evaluation method" to further reform and promote this teaching model and assessment model.

In addition, it should promote the in-depth integration of information technology with education and teaching, strengthen the construction of open online courses represented by MOOC and SPOC, and form an open online course system with school advantages and characteristics. Moreover, high-quality online course resources at home and abroad should be introduced to enrich teaching resources on campus and promote the sharing of high-quality education resources. In the meantime, it should explore the classroom teaching mode that combines online learning with offline learning, the academic evaluation method that combines online assessment with offline examination, and use "Internet plus" modern information technology to promote the innovation of teaching mode, teaching method and teaching means.

\subsection{Promoting education in innovation and entrepreneurship in a coordinated way to cultivate students' innovation ability and entrepreneurial awareness.}

It should strengthen the institutional building, promote the organic integration of professional education with innovation and entrepreneurship education, highlight the cultivation of students' innovative ability and entrepreneurial awareness, and establish new mechanism for adjusting the structure of personnel training oriented towards entrepreneurship and employment. What's more, new models of school-school, school-enterprise, school-local, school-institutes and international cooperation should be improved, and off-campus practice bases for innovation and entrepreneurship and training centers for innovation and entrepreneurship talents should be built. At the same time, a number of open maker spaces should be built by relying on laboratories, research platforms and engineering centers at all levels. And it should build platforms to support innovation and entrepreneurship, give preferential policy to those technological enterprises, and establish a demonstration support platform system for the whole chain of entrepreneurship and innovation education, entrepreneurship nursery, project incubator and achievement accelerator.

\subsection{Implementing the training mode by combining major degree with minor degree to cultivate compound top-notch innovative talents}

To meet the needs of national economic construction and social development for interdisciplinary professionals, it should broaden the personalized training approaches and implement the talent training mode of "major + minor". On the one hand, it promotes the integration of science, engineering, literature, medicine, economics and management law and other disciplines; On the other hand, it cultivates the all-round top-notch innovative talents to meet the needs of the society and enhances students' social competitiveness.

\section{TO COOPERATE WITH MULTIPLE PARTIES TO CONSTRUCT AN ALL-ROUND COORDINATED EDUCATION MECHANISM}

It is essential for the university to take open-minded to combine "bringing in" with "going out" to run our school, and take the initiative to evaluate school quality and effectiveness together with government, industry, society and international counterparts with a strong sense of serving the national strategy. Meanwhile, it should continue to explore new mechanisms for joint talent 
training and collaborative innovation with research institutes, industrial enterprises and foreign universities and enterprises to create an excellent environment for the university's reform and development.

\subsection{Opening our laboratory to stimulate students' interest and cultivate their scientific research ability}

Since 2012, our university has implemented the laboratory opening system, strengthened hardware and soft environment construction, and improved the relevant supporting policies and incentive mechanism. By doing so, students are encouraged to research at early stage and get to know laboratory at early age. We support students to explore freely, research and practice, innovate and participate in discipline competitions. And the teaching laboratory is fully open to undergraduate students, and part of scientific research laboratory is open to undergraduate students, so as to realize the "three promotions" for undergraduate talent cultivation, that is, promoting the combination of science and education, promoting interdisciplines, and promoting innovative education.

In order to cultivate talents with innovative spirit and systematic thinking who adapt to new economic development and are eager to collaborate with people from different fields, we further encourage innovative, comprehensive and research-based experimental programme which involve in interdiscipline in the process of laboratory opening. We build a unified platform in the university to attract teachers from different subjects and departments for in-depth cooperation, make full use of existing scientific research platforms, laboratory resources and teachers to jointly create interdisciplinary open experimental projects and strengthen students' ability in teamwork, system integration, practice and innovation.

\subsection{Improving the mechanism of cooperation among production, education and research, strengthening the construction of off-campus practice education bases, and train students' practical ability}

In addition to strengthening the cooperation between universities and enterprises, it should also pay attention to strengthening the multi-party cooperation among universities, governments and research institutes, so as to realize the collaborative education among enterprises, universities and research institutes. Through the "excellence initiative", an in-depth exploration on coordinated education mechanism which is led by government, guided by industry participated by colleges and promoted by institutions of high learning should be made. In addition, it should establish a good ecological system for cooperative education, expand the function and connotation of off-campus practice base, and optimize the operation and management mechanism of the base in order to create a long-term mechanism and win-win mode of schools and industry cooperation talent training and establish and implement supervisor selection and evaluation system in the base. According to specialty characteristics and industry dynamic demand, we cooperate with enterprises to explore and optimize the operation and management mechanism of the base, and further innovate the teaching and management mode of off-campus base by improving training standards, training programs, training management and quality control. Meanwhile, we cooperate with enterprises for undergraduate graduation project (thesis) and for the guidance of college students innovation and entrepreneurship project.

\subsection{Strengthening international exchanges and cooperation to cultivate students' international competitiveness}

By promoting cooperation with internationally renowned universities, it should implement undergraduate cooperation programs such as " $2+2$ " and " $3+1+\mathrm{N}$ ", exchange international students and recognize credit and degree of foreign universities and colleges. Moreover, an international talent training base should be built to help students' realize overseas internship, summer vacation plan, short-term study abroad, etc. Through the cooperation in running schools and the construction of internationalized talents cultivation base, on the one hand, we can expand students' international vision, make them have international awareness, enhance their ability in intercultural communication, cooperation and participation in international competition; On the other hand, with the help of the first-class education resources curriculum resources and teaching conditions from developed countries, we can construct and develop new engineering discipline.

It is critical for the university to serve the national strategy of "the Belt and Road" and "Made in China 2025". By relying on stomatology, agricultural engineering, Hezhe ethnic culture in Sanjiang region, we base on Sanjiang to servie Longjiang and orient toward the national medical and health, agriculture, and other large enterprises. In the meantime, we strengthen the foundation of engineering talents in law, economics, enterprise management and foreign languages. Through industry-education-research cooperation, on the one hand, we can cultivate a number of international compound senior engineering talents with ability in intercultural communication and comprehensive management who are familiar with international laws; On the other hand, we can understand global industrial demands for engineering talents so as to reform the curriculum system, personnel training mode, teaching content and methods, etc., thus improving the international competitiveness and influence of engineering education. 


\section{TO BUILD AN EVALUATION SYSTEM FOR TEACHING QUALITY WITH STUDENTS' LIFELONG LEARNING ABILITY AS THE CORE}

\begin{abstract}
New engineering talents cultivation goal actively orients toward national strategies such as "Made in China" 2025" and the Belt and one Road. Therefore, it should strengthen students intercultural collaboration and leadership development, broaden their international vision, promote their ability in cross-border communication, interdisciplinary knowledge migration and lifelong learning in order to adapt to the fast-changing new economy development and social needs. In the practice of the senior engineering personnel training, our university breaks the institutional barrier where society participates in the talent cultivation and promotes college-enterprise cooperation at multi-level and multi-field to boost enterprises and colleges to think about key problems of talents cultivation. Through diversified evaluation, we further improve the performance evaluation and feedback mechanism of the talents training target, thus forming quality evaluation mechanism for talent training.
\end{abstract}

\subsection{Constructing the double closed-loop control system for talent cultivation quality before and after feedback}

It should build a teaching quality guarantee system with "students' learning development" and "teachers' teaching development" as the core and improve the linkage mechanism of teaching quality management. By doing so, we can control the teaching quality before feedback which actively meets the needs of national social and economic development and form external quality feedback control oriented toward social needs and double closed-loop control system of internal quality feedback control oriented toward teaching objectives before and after feedback, thus cultivating talents in an all-round manner in the whole process with all people involved in to ensure the quality of talents cultivation.

\subsection{Building a big data platform with integrated data acquisition, analysis, and feedback functions}

It should analyze and use data from demand analysis, process management and quality evaluation by using big data analysis method, establish diversified information feedback mechanism, and provide a reliable supporting platform for continuous improvement of quality.

\subsection{Improving teaching quality evaluation and incentive mechanism}

It should strengthen the monitoring teaching process, and further improve the quality evaluation system which integrates five aspects into one: that is, audit and evaluation from colleges, data release of basic teaching status, professional certification and evaluation, curriculum evaluation and teaching quality evaluation. In addition, the evaluation results in student evaluation, supervisors' evaluation and colleague evaluation should be reasonably used to form evaluation mechanism combining qualitative and quantitative evaluation for teachers' teaching quality. It should evaluate course construction (including course resources, teaching staff, teaching content, teaching research and teaching reform, etc.) comprehensively and have a special research and evaluation of ideological and political courses, freshmen courses, general education courses, public courses and other courses. More importantly, the mechanism construction such as college audit and evaluation, data release of basic teaching status, professional certification and evaluation should be improved. We can use information technology to implement normal monitoring of teaching status data, and improve the evaluation system of secondary colleges based on the idea of audit and evaluation.

\section{CONCLUSION}

The new engineering construction path based on interdisciplinary integration is a concrete measure to integrate engineering education into the new engineering concept and embodies the professional certification concept featured by student-centered, results-oriented and continuous improvement. Through enrollment and cultivation under broader categories, we can optimize professional structure, implement "student-centered" talent training mode reform, and build all-round cooperative education mechanism among multiple parties and teaching quality evaluation system with students' lifelong learning ability as the core, thus forming closed-loop cultivation for new engineering talents and effectively promoting their innovation ability.

\section{ACKNOWLEDGMENT}

Fund project: jointly funded by the Second Batch of National New Engineering Research and Practice Project Exploration and Practice on Cultivating Innovation and Entrepreneurship Ability of Engineering Talents Under New Engineering Background (E-CXCYYR20200921) and Heilongjiang Higher Education Teaching Reform Project Exploration and Practice on College Students' Innovation and Entrepreneurship Education and Its Integrated Progressive Support System Under New Engineering Background. 


\section{REFERENCES}

[1] Hu Dexin. On Institutional Dilemma and Action Path of New Engineering Construction from the Perspective of Discipline Evolution[J]. Research in Higher Education of Engineering, 2020, (03):49-54.

[2] Zhang Fengbao. Discussion on the Path and Method of New Engineering Construction-The Exploration and Practice of Tianjin University[J]. China University Teaching, 2017, (07):8-12.

[3] Entrance Examination Reform[J]. China Higher Education, 2018, (06):64.

[4] On Construction Action Route of "New Engineering" ("Tianda Action")[J]. Research in Higher Education of Engineering, 2017, (02):24-25.

[5] On Fudan Consensus on "New Engineering" [J]. Research in Higher Education of Engineering, 2017, (01):10-11.

[6] Ma Xiaojun, Li Chunjiang, Xing Chuanbo, Ma Huaquang, Zhang Hongwei, Analysis of New Engineering and Current Situation of its Practice in Local Universities[J]. The Theory and Practice of Innovation and Entrepreneurship, 2021, 4(05):1-3+6.
[7] Li Chunjiang, Ma Xiaojun, Wang Xinxin, Exploring the Path and Method of New Engineering Construction in Local Universities[J]. The Theory and Practice of Innovation and Entrepreneurship, 2021, 4(04):139-141+144.

[8] Li Chuanjiang, Ma Xiaojun, Pan Hongwei, Lijing, On Exploration on New Engineering Practice of Agricultural Electrification Major in Local Universities[J]. The Theory and Practice of Innovation and Entrepreneurship, 2021, 4(03):109-111.

[9] Ma Xiaojun, Zhang Ze, Li Chunjiang, Zhao Baojiang, On the Thought Guidance of New engineering Talent and on the System Construction and Implementation Path of Innovation and Entrepreneurship Course[J]. Educator (Higher Education Forum), 2020, (03):74-75.

[10] Ma Xiaojun, Li Chunjiang, Song Hanjun, Zhao Baojiang, Yan Bingbing, On Strategies for Cultivating Innovative Ability of New Engineering Talents in Local Universities[J]. Journal of Hubei Adult Education Institute, 2018, 24(04):19-21. 